\title{
Mathematical Model for Finding Relation Between Asthma And The HPA Axis By Using MDE
}

\author{
S. Lakshmi * and M. Senbagavalli ** \\ * Principal, Government of Arts and Science College, Peravurani-614804, Thanjavur, TamilNadu. \\ ** Research Scholar, UG\&PG Research Department of Mathematics, Kunthavai Naacchiyaar Govt. Arts \\ College for Women (Autonomous), Thanjavur, TamilNadu.
}

\begin{abstract}
The objectives of this paper are to review the relation between Asthma and the HPA axis suppression and its clinical significance in adults and children and to describe methods for diagnosing HPA axis suppression and to explain the implication on selection of treatment for asthma and allergic diseases. Prolonged periods of stress can cause cortisol levels remain elevated, so that some aspects of immune system function continue to be suppressed. This makes the person more susceptible to infections and illness. At the same time, other aspects of the immune system may become unbalanced, which can increase the risk of developing an autoimmune disease, in which the immune system attacks the body's own cells. Cortisol's connections to other body systems mean that it can influence allergies. Since hormones play such an important role in regulating the incidence and severity of allergies, it's not surprising that they also play a role in allergy treatment. Synthetic hormones are used to treat many types of allergies. The Mathematical result for the above applications include the identification of classes of distributions based on mean residual life inequality constraints, where the well known model are Maximum dynamic entropy and its development of classes of distributions whose mean residual life functions are bounded.
\end{abstract}

\subsection{MATHEMATICAL MODEL}

\section{INTRODUCTION}

Minimum cross-entropy principle is a generalization of the Maximum Entropy (ME) principle for the development of models close to any given distribution instead of the uniform distribution [12]. A Maximum Dynamic Entropy (MDE) procedure for developing lifetime models has been proposed. This may be viewed as an extension of the ME principle in the case that the information is given in terms of hazard rate growth inequality constraints $[2,9]$.

Consider a set of distribution $\Omega_{\mathrm{F}}=\{\mathrm{F}\}$, where $\mathrm{F}$ has PDF $\mathrm{f}$ and is absolutely continuous with respect to a reference distribution $\mathrm{G}$ that has PDF $\mathrm{g}$. The MDDI model in $\Omega_{\mathrm{F}}$ relative to $\mathrm{G}$ is $\mathrm{F}^{*}$, with PDF $\mathrm{f}^{*}$ such that $\mathrm{K}\left(\mathrm{f}^{*}: \mathrm{g} ; \mathrm{t}\right)$ for all $\mathrm{t} \geq 0$.

The following theorem gives the properties of the MDDI distributions in classes of distributions with mean residual life in equality constraints.

\section{Throrem 1.1:}

Let $\Omega_{\mathrm{F}}=\{\mathrm{F}: \mu F(t) \leq q(t)\}$ be a compact set of distributions, where $\mathrm{F}$ is absolutely continuous with respect to a reference distribution G. Let $\mathrm{F}^{*} \in \Omega_{\mathrm{F}}$ be such that $\mu F(t)=q(t)$. If $\log \left(\mathrm{f}^{*}(\mathrm{x}) / \mathrm{g}(\mathrm{x})\right)$ is decreasing and concave then $\mathrm{F}^{*}$ is the MDDI distribution relative to $\mathrm{G}$. The same result holds, with $\Omega_{\mathrm{F}}=$ $\{\mathrm{F}: \mu F(t) \geq q(t)\}$. if $\quad \log \left(\mathrm{f}^{*}(\mathrm{x}) / \mathrm{g}(\mathrm{x})\right)$ is increasing and convex .

Proof:

$$
\begin{aligned}
& \text { We will prove the case in which } \mu F(t) \leq q(t) \text {. First, note that } \\
& \begin{aligned}
\mathrm{K}(\mathrm{f}: \mathrm{g} ; \mathrm{t})= & \int_{\mathrm{t}}^{\infty} \mathrm{f}(\mathrm{x} ; \mathrm{t}) \log \frac{\mathrm{f}(\mathrm{x} ; \mathrm{t})}{\mathrm{g}(\mathrm{x} ; \mathrm{t})} \mathrm{dx} \\
& =\int_{\mathrm{t}}^{\infty} \mathrm{f}(\mathrm{x} ; \mathrm{t}) \log \frac{\mathrm{f}^{*}(\mathrm{x} ; \mathrm{t})}{\mathrm{g}(\mathrm{x} ; \mathrm{t})} \mathrm{dx}+\int_{\mathrm{t}}^{\infty} \mathrm{f}(\mathrm{x} ; \mathrm{t}) \log \frac{\mathrm{f}(\mathrm{x} ; \mathrm{t})}{\mathrm{f}^{*}(\mathrm{x} ; \mathrm{t})} \mathrm{dx} \\
& \geq \int_{\mathrm{t}}^{\infty} \mathrm{f}(\mathrm{x} ; \mathrm{t}) \log \frac{\mathrm{f}^{*}(\mathrm{x} ; \mathrm{t})}{\mathrm{g}(\mathrm{x} ; \mathrm{t})} \mathrm{dx},
\end{aligned}
\end{aligned}
$$

Where the inequality is due to the fact that the second integral in (1) equals $K$ (f: $\left.f^{*} ; t\right) \geq t$.

This gives

$$
\begin{aligned}
K(f: g ; t)-K\left(f^{*}: g ; t\right) \geq & \int_{t}^{\infty} f(x ; t) \log \frac{f^{*}(x ; t)}{g(x ; t)} d x-\int_{t}^{\infty} f^{*}(x ; t) \log \frac{f^{*}(x ; t)}{g(x ; t)} d x \\
& =\int_{t}^{\infty} f(x ; t) \log \frac{f^{(x}(x)}{g(x)} d x-\int_{t}^{\infty} f^{*}(x ; t) \log \frac{f^{*}(x)}{g(x)} d x \\
& \geq 0 .
\end{aligned}
$$


Since $\log \left(\mathrm{f}^{*}(\mathrm{x}) / \mathrm{g}(\mathrm{x})\right)$ is decreasing and concave and $\mu F(t) \leq q(t)=\mu F^{*}(t)$, the last inequality follows from theorem [11]. The Proof for $\mu F(t) \geq q(t)$ is similar.

When $G$ has a uniform PDF over $\{\mathrm{x}: 0<\mathrm{x}<\mathrm{b}\}$, the residual life PDF $\mathrm{g}(\mathrm{x} ; \mathrm{t})$ is also uniform over $\{\mathrm{x}$ : $\mathrm{t}<\mathrm{x}<\mathrm{b}\}$ and the MDDI model reduces to the MDE model. The MDE model in a set of distribution $\Omega_{\mathrm{F}}=\{\mathrm{F}\}$ is the distribution with $\operatorname{PDF} \mathrm{f}^{*}(\mathrm{x})$ such that

$\mathrm{H}(\mathrm{f} ; \mathrm{t}) \leq \mathrm{H}\left(\mathrm{f}^{*} ; \mathrm{t}\right)$ for all $\mathrm{t} \geq 0$.

\section{Corollary 1:}

Let $\Omega_{\mathrm{F}}=\{\mathrm{F}: \mu F(t) \leq q(t)\}$ be a compact set of absolutely continuous distributions. Let $\mathrm{F}^{*} \in \Omega_{\mathrm{F}}$ be such that $\mu \mathrm{F}^{*}(\mathrm{t})=\mathrm{q}(\mathrm{t})$. If $\log \mathrm{f}^{*}(\mathrm{x})$ is increasing and $\log$ convex then $\mathrm{F}^{*}$ is the MDE distribution. The same results holds, with

$$
\Omega_{\mathrm{F}}=\{\mathrm{F}: \mu F(t) \geq q(t)\}
$$

If $f^{*}(\mathrm{x})$ is decreasing and log-concave.

Applications of the above results include the identification of classes of distributions based on mean residual life inequality constraints, where the well-known models are MDE, and the development of MDE models for classes of distributions whose mean residual life functions are bounded by a given function q ( t ) [3,5]. Any continuous function $\mathrm{q}(\mathrm{t})$ with the following properties is the mean residual life function of a distribution function $\mathrm{F}$ :

$$
\begin{aligned}
& -0 \leq q(t)<\infty ; \\
& \text { - } \mathrm{q}(0)>0 ; \\
& \text { - }(t)+1>0 ; \\
& \text { - }\left\{\begin{array}{c}
\mathrm{q}(\mathrm{t} 0)=0 \text { for some } \mathrm{t} 0 \text { then } \mathrm{q}(\mathrm{t})=0 \text { for all } \mathrm{t} \geq \mathrm{t} 0 \\
\text { if } \mathrm{q}(\mathrm{t})>0 \text { for all } t>0 \text { then } \int_{0}^{\infty}\left(\frac{1}{\mathrm{q}(\mathrm{t})}\right) \mathrm{dt}=\infty .
\end{array}\right.
\end{aligned}
$$

For any function satisfying (i) - (iv), we can obtain a unique distribution given by the dynamic extensions of the MDI and ME principles in terms of the residual moments. The mean residual life function is defined by

$$
\mu F(t)=E[X-t \mid X>t]= \begin{cases}\frac{1}{\overline{\mathrm{F}}(\mathrm{t})} \int_{\mathrm{t}}^{\infty} \overline{\mathrm{F}}(\mathrm{x}) \mathrm{dx} & \text { if } \bar{F}(t)>0, \\ 0 & \text { if } \bar{F}(t)=0 .\end{cases}
$$

However, the mean residual life uniquely determines the lifetime distribution [6]; that is,

$$
\bar{F}(t)=\frac{\mu F(0)}{\mu F(t)} \exp \left\{-\int_{0}^{t} \frac{1}{\mu F(x)} d x\right\} .
$$

Then for any reference distribution, the conditions of theorem 1 can easily be verified by comparing the first and second derivatives of the two densities: $\mathrm{f}(\mathrm{x}) / \mathrm{g}(\mathrm{x})$ is increasing or decreasing if

$$
\frac{d \log f(x)}{d x} \geq \frac{d \log g(x)}{d x} \quad \text { or } \quad \frac{d \log f(x)}{d x} \leq \frac{d \log g(x)}{d x}
$$

respectively, and $\log (f(x) / g(x))$ is convex or concave if

$$
\frac{d^{2} \log f(x)}{d x^{2}} \geq \frac{d^{2} \log g(x)}{d x^{2}} \quad \text { or } \quad \frac{d^{2} \log f(x)}{d x^{2}} \leq \frac{d^{2} \log g(x)}{d x^{2}}
$$

Respectively [7]. Under the conditions of Corollary 1, the right-hand sides of both (1.3) and (1.4) equal 0.

The natural choice of reference distribution in lifetime analysis is the exponential distribution with PDF

$$
g_{e}(x ; \lambda)=e^{-\lambda x}, \quad \lambda>0, \mathrm{x} \geq 0 .
$$

For the exponential reference distribution, the right-hand side of (1.3) equals $-\lambda$ and the right-hand side of (1.4) equals 0 . That is, $\log (\mathrm{f}(\mathrm{x}) / \mathrm{g}(\mathrm{x}))$ is concave or convex if $\mathrm{f}(\mathrm{x})$ is $\log$-concave or log-convex, respectively. Furthermore, $\mathrm{K}\left(\mathrm{f}: g_{e}\right)$ is well defined if $\mathrm{F}$ has positive support, finite entropy, and finite mean. These conditions hold for all distributions presented in this paper.

\section{Corollary 2:}

Let $\mathrm{q}(\mathrm{t})=\mu$ for all $\mathrm{t}$. It is clear that $\mathrm{q}(\mathrm{t})$ satisfies (i) - (iv). Then (1.2) gives the exponential distribution with PDF $\mathrm{f}(\mathrm{x})=(1 / \mu) e^{-x / \mu}$. The exponential distribution PDF is decreasing and log-concave. By Corollary 1, this is the MDE model in the class of distributions with mean residual life $\mu F(t) \leq \mu$.

The MDE model relative to the exponential distribution, with mean residual inequality constraints for generalized normal combination

$$
\begin{aligned}
& \mathrm{f}^{*}(\mathrm{x})=\frac{e^{\beta^{2} / 2 \alpha}}{\beta}\left[\frac{(\mathrm{x}+\beta)^{2}}{\alpha}-1\right] \mathrm{e}^{-(1 / 2 \alpha)(\mathrm{x}+\beta)^{2}} \quad \text { with } 0<\alpha<\beta^{2} \\
& \mu F(t) \leq \frac{\alpha}{\mathrm{t}+\beta} \quad \beta^{2}>3 \alpha, \quad \beta^{2} \geq 3 \alpha, \quad \lambda \leq \frac{\beta\left(\beta^{2}-3 \alpha\right)}{\alpha\left(\beta^{2}-\alpha\right)}
\end{aligned}
$$

2.1 Asthma and the HPA axis

II. APPLICATIONS 
The objectives of this paper are to review HPA axis suppression and its clinical significance in adults and children and to describe methods for diagnosing HPA axis suppression and to explain the implication on selection of treatment for asthma and allergic diseases [1,5]. When giving Exogenous Prednisone or Dexamethasone for three weeks

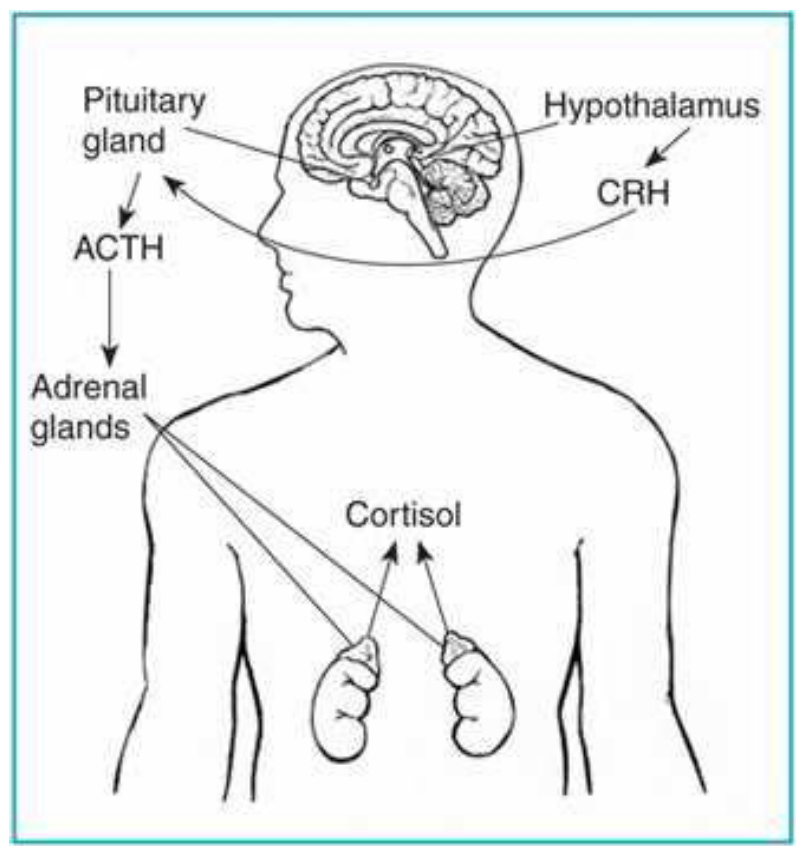

When CRH, ACTH and Cortisol are decreased and decreased response to stimulation with Cosyntropin.

Treatment of Asthma and the HPA axis is related to the implications of HPA suppression which leads to subnormal secretion of Cortisol, suppression of growth, Osteopenia, severe Myalgia, Weakness, Fatigue, inability to respond to stress (surgery, shock, sepsis etc) and Cushingoid obesity/ syndrome $[8,10]$. But no clinical adverse effects and asymptomatic. Asthmatic HPA axis suppression and its clinical significance to describe methods for diagnosing HPA axis suppression and to explain the implication on selection of treatment for asthma and allergic diseases [13].

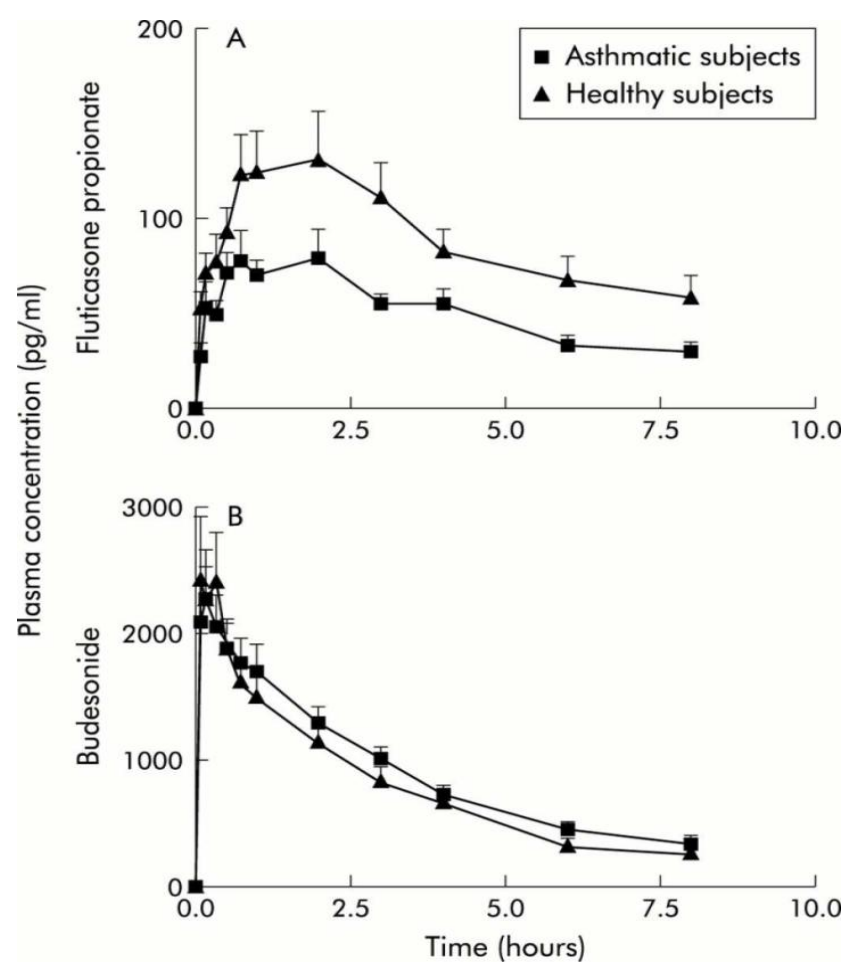


Mean(SE) plasma concentrations of (A) fluticasone propionatew and (B) Budesonide in health subjects and subjects with moderately severe Asthma

\subsection{Relevant to Asthma}

Adrenal Insufficiency $\Rightarrow$ ( i ) Primary ( Addisons Disease...Autoimmune, TB )

(ii ) Secondary ( Corticisteroids )

Primary study outcomes- is there blunted or reduced basal HPA axis -serum cortisal, dynamic HPA axisresponse to low dose cosyntropin and clinically meaningful suppression is when cosyntropin response is impaired in patients with asthma $[4,15]$.

Diagnosis of secondary adrenal insufficiency from corticosteroids to the background of oral or high orally inhaled corticosteroids block release of $\mathrm{CRH}$ and ACTH, low cortisol, impaired response to ACTH and impaired or no response to CRH [14].

\section{MATHEMATICAL RESULT}

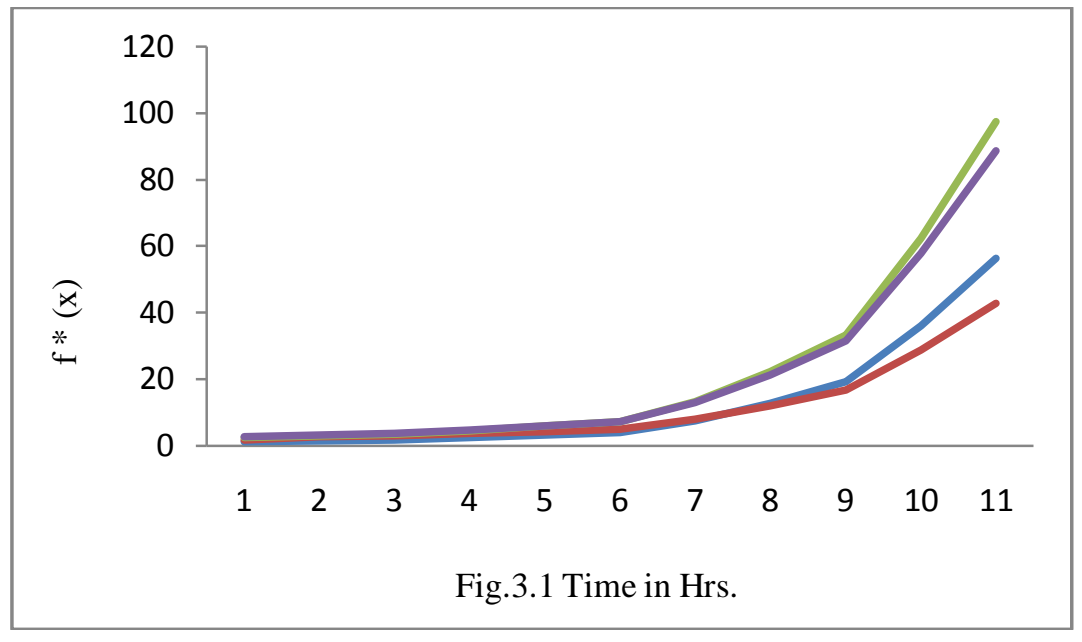

\section{CONCLUSION}

The Mathematical result for the above applications include the identification of classes of distributions based on mean residual life inequality constraints, where the well known model are Maximum dynamic entropy and its development of classes of distributions whose mean residual life functions are obtained and are bounded. MDE model relative with mean residual inequality constraints for the density functions are obtained and well defined in the above Fig.3.1. When the rate of the parameters of $\alpha$ and $\beta$ of the corresponding medical curves in the cases of Asthmatic and Healthy subjects are increased the corresponding probability density functions are also increased.

Combinations of intranasal and orally inhaled corticosteroids in recommended doses would not cause HPA axis abnormalities. First pass effect (liver metabolism) minimizes oral bioavailability ( Fluticasone, Mometasone, Budesonide ). Systemic absorption of inhaled Corticosteroid dry power inhalers in patients matters less in patients with asthma compared to normal subjects, drug specific. There is no additive HPA suppression, when there is nasal and Bronchial administration.

\section{ACKNOWLEDGEMENT}

This work have been carried out by the authors under the MRP fund of UGC XI Plan from Government of India, New Delhi.

\section{REFERENCES}

[1] Akerman MJ , Calacanis CM , Madsen MK . Relationship between asthma severity and obesity . J Asthma . $2004 ; 41$ ( 5 ): $421-526$.

[2] Asadi, M., Ebrahimi, N., Hamedani, G. G. And Soofi, E. S. (2004). Maximum dynamic entropy models. J. Appl. Prob, 41, 379- 390.

[3] Belzunce, F., Navarro, J., and Del Aguila, Y. (2004). Some results on residual entropy functions. Metrika 59, 147- 161.

[4] Brozek JL, Bousquet J, Baena-Cagnani CE, Bonini S, Canonica GW, Casale TB, et al. Allergic rhinitis and its impact on asthma (ARIA) guidelines: 2010 revision. J Allergy Clin Immunol. 2010;126:466-76. 
[5] Collins LC, Hoberty PD, Walker JF, Fletcher EC, Peiris AN. The effect of body fat distribution on pulmonary function tests . Chest . $1995 ; 107$ ( 5 ): 1298 - 1302 .

[6] De Crescenzo, A., and Longobardi, M., (2002). Entropy - based measure of uncertainty in past lifetime distributions. J. Appl. Prob, 39, 434- 440.

[7] Ebrahimi, N., (2001) Testing for uniformity of the residual lifetime based on dynamic Kullback-Leibler information. Ann. Inst. Statist. Math. 53, 325-337.

[8] Hjellvik V , Tverdal A , Furu K . Body mass index as predictor for asthma: a cohort study of 118,723 males and females . Eur Respir J . 2010 ; 35 ( 6 ): 1235 - 1242.

[9] Jaynes, E. T.,(1982). On the rationale of maximum entropy methods. Proc. IEEE 70, 939-952.

[10] Lugogo N, Que LG, Fertel D, Kraft M. Asthma. In: Mason RJ, Broaddus VC, Martin TR, et al., eds. Murray \& Nadel's Textbook of Respiratory Medicine. 5th ed. Philadelphia, Pa.: Elsevier Saunders; 2010:chap 38.

[11] Shaked, M. And Shanthikumar, J. G., (1994). Stochastic orders and their applications. Academic Press, Boston, MA.

[12] Shore, J. E., and Johnson, R.W. (1980). Axiomatic derivation of the principle of maximum entropy and principle of minimum cross- entropy. IEEE Trans. Inf. Theory 26, 26-37.

[13] Taylor B , Mannino D, Brown C, Crocker D, Twum-Baah N, Holguin F . Body mass index and asthma severity in the National Asthma Survey. Thorax . 2008; 63 ( 1 ): 14 - 20 .

[14] Ford ES . The epidemiology of obesity and asthma . J Allergy Clin Immunol . 2005 ; 115 ( 5 ): 897 - 909.

[15] Taylor B , Mannino D, Brown C, Crocker D, Twum-Baah N , Holguin F . Body mass index and asthma severity in the National Asthma Survey. Thorax . $2008 ; 63$ ( 1 ): 14 - 20 . 